\title{
A MUDANÇA CULTURAL DA GESTÃO JUDICIAL: INOVAÇÃO COMO BASE DA BUSCA DA EXCELÊNCIA DO SERVIÇO PÚBLICO
}

\section{THE CHANGE OF CULTURE OF THE JUDICIAL MANAGEMENT INNOVATION: AS THE BASIS OF THE SEARCH FOR EXCELLENCE IN THE PUBLIC SERVICE}

Luciana Ortiz Tavares Costa Zanoni*

\begin{abstract}
RESUMO
O presente capítulo procura explorar a cultura da inovação na gestão judicial processual e administrativa. Busca-se também trazer as reformas da função do Estado promovidas nas últimas décadas, assim como a adoção dessas mudanças gerenciais e inovadoras para dentro da administração pública brasileira, especialmente para o Judiciário. Por fim, o texto propõe referencial para inovar no Judiciário, apresentando a experiência do iNovaJusp (Programa de Gestão e Inovação) e do iJuspLab (Laboratório de Inovação), ambas experiências criadas e implementadas na Justiça Federal de São Paulo.

Palavras-chave: Conhecimento; Eficiência no serviço público; Inovação; Inovação em governo; Inovação no Judiciário; Gestão Judicial Processual e Administrativa; Inovação organizacional; Mudança cultural; Novos modelos de negócio.
\end{abstract}

Juíza Federal e Diretora do Foro da Justiça Federal do Estado de São Paulo. Vice-Diretora do Foro da Justiça Federal do Estado de São Paulo (2016/2017). Presidente do Juizado Especial Federal de São Paulo (2010/2011). Diretora da Associação dos Juízes Federais do Brasil (2014/2015). Mestre em Direito pela Pontifícia Universidade Católica - Puc-SP. Mestre em Gestão e Políticas Públicas - Fundação Getulio Vargas. Cofundadora, juntamente com o Juiz Federal Paulo Cezar Neves Junior, do Laboratório de Inovação da Justiça Federal (iJuspLab). 


\begin{abstract}
This chapter seeks to explore the culture of innovation of the judicial case management and administrative management of the Judiciary. It also seeks to bring the reforms of the state function promoted in the last decades, as well as, the adoption of these managerial and innovative changes to the Brazilian public administration, in special to the Judiciary. Finally, the text proposes a reference for innovation in the Judiciary, by presenting the experience of iNovaJusp (Program of Management and Innovation) and the iJuspLab (Innovation Laboratory), both experiences designed and implemented in the Federal Court of São Paulo.
\end{abstract}

Keywords: Knowledge; Efficiency in public service; Innovation; Innovation in government; Case Management and administrative Management of the Judiciary Organizational innovation; Cultural change; New business models.

\title{
A ERA DO CONHECIMENTO E INOVAÇÃO NO SETOR PÚBLICO
}

A questão que se põe no dia a dia da administração é: como inovar no setor público? Nós servidores ou agentes políticos somos condicionados a atuar estritamente dentro da legalidade. Seguimos à risca as normatizações. E não só isso, carregamos de geração em geração os procedimentos adotados ao longo do tempo, burocracias criadas pelo espírito burocrático. É comum perguntamos o porquê de determinado procedimento e a resposta ser "porque sempre foi feito assim", ou os procedimentos estarem na cabeça do gestor, que leva o conhecimento institucional de "como os procedimentos funcionam" para as férias e licenças, ficando a administração estagnada aguardando o seu retorno. $\mathrm{O}$ quadro se agrava em tempos de aposentadorias precoces decorrentes do receio da perda de direitos adquiridos. É corriqueiro, ainda, iniciativas de mudanças serem engavetadas pois a lei ou normativos disciplinam ou estão para ser disciplinados pela alta administração, o que paralisa novas iniciativas. Além disso, soluções normatizadas frequentemente estão distantes dos problemas diários, dificultando a implementação da solução. Esses são alguns casos em que a burocracia engessa a administração e freia um serviço de melhor qualidade.

E isso acontece porque até a década de 1990, a administração pública brasileira manteve-se arraigada ao modelo burocrático. Fomos educados e orientados a agir cumprindo o expediente do dia, o limite do possível dentro do modelo traçado pela lei e pelos normativos. Assim agindo cumpríamos o nosso desiderato institucional. 
Entretanto, a partir da década de 1960, a tendência foi a de repensar a função do Estado, movimento impulsionado pelas ondas de desenvolvimento tecnológico, consolidação da democracia e a ampliação dos direitos sociais.

Nos países anglo-saxões, importou-se da iniciativa privada conceitos gerencias, para imprimir melhores resultados que atendessem o interesse público, movimento cunhado de Nova Gestão Pública (New Public Management). Nos países de tendência mais burocrática, desenvolveu-se o Estado Neoweberiano (modelo Neo Weberian State), que também adotou conceitos para tornar o estado mais profissional, mais eficiente, com análise de desempenho, diálogo com o cidadão para extrair suas necessidades e expectativas, e modernização. A teoria da governança pública (New Public Governance), variante da Nova Gestão Pública, tem como foco tornar o governo mais eficaz e legítimo, com maior participação do cidadão nas definições das políticas públicas. Esses modelos se modificaram e se adaptaram à estrutura constitucional e social dos países que os adotaram. ${ }^{1}$

O fato é que, qualquer que seja o modelo, busca-se trazer para o seio do Estado a construção do serviço público que produza um resultado efetivo, eficaz e eficiente para o cidadão. Nesse sentido, identificam-se pontos em comum entre os modelos supramencionados, como a organização e transparência dos dados, espaços dialogados com o usuário, parcerias institucionais, modernização e informatização. Inegável, assim, que a inovação está no centro da transformação do serviço público.

Figura 1. Filtro da inovação.

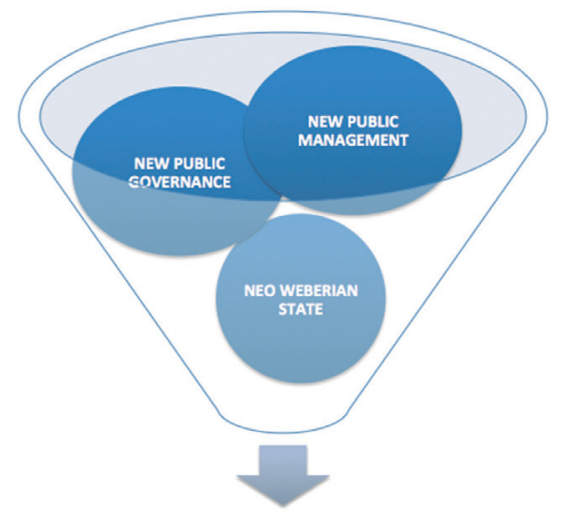

Eficiência: inovação

Fonte: Elaborada pela autoria.

1 POLLITT, Christopher; BOUCKAERT, Geert. Public management reform, p. 22. 
Dentro deste cenário, a administração pública brasileira promoveu nas duas últimas décadas grandes transformações, sobretudo com a reforma constitucional de 1998 que introduziu a Nova Gestão Pública, quando impôs ao administrador público a visão gerencial, na qual o ponto central era maior eficiência no serviço público. O Plano Diretor da Reforma do Aparelho do Estado 2 dividiu o a estrutura estatal em quatro setores, a saber: Núcleo Estratégico (Poderes Legislativo e Judiciário, o Ministério Público e, no Poder Executivo, o Presidente da República, os ministros e seus auxiliares e assessores diretos, responsáveis pelo planejamento e formulação de políticas públicas), correspondente ao governo, onde se define as leis e as políticas públicas e se cobra o seu cumprimento; Atividades Exclusivas; Serviços não Exclusivos; Produção de Bens e Serviços para o mercado.

De forma que o Judiciário integra o Núcleo Estratégico, no qual "o fundamental é que as decisões sejam as melhores e, em seguida, que sejam efetivamente cumpridas", além de disso se impôs a gestão estratégica como forma de se imprimir eficiência ao serviço. A adoção do modelo gerencial também no Poder Judiciário constitui desiderato constitucional, a fim de fazer uma entrega com qualidade em menor tempo.

O Judiciário tem envidado esforços para introduzir mudanças gerenciais que propiciem o planejamento estratégico que retrate a realidade da instituição e planeje seu futuro, orçamento programa, organização e transparência dos dados, avaliação de desempenho e gestão dos fluxos do trabalho.

Contudo, uma leitura mais acurada do texto constitucional, e aprofundando o princípio da eficiência, emerge a necessidade de que o serviço público seja inovador, de forma a atingir, ou superar, as expectativas do cidadão. Essa leitura vem ao encontro das grandes transformações decorrentes das revoluções digitais. É a era do conhecimento e inovação, na qual as inovações imprimem modificações profundas nas organizações e nas relações sociais, sobretudo em razão dos avanços exponenciais da tecnologia. As possibilidades de mudança são imensas, assim como as necessidades do setor público, que presta, em grande parte, um serviço público sofrível.

A Comissão Europeia tem trazido à reflexão como a democracia pode ser renovada e preservada para o futuro, promovendo mudanças nas relaçóes de poder, nas tomadas de decisão e geração de valor público, bem por isso tem recomendado

2 A reforma foi produzida pelo Ministério da Administração Federal e da Reforma do Estado (Mare), responsável pela introdução do modelo gerencial no Brasil. 
nas duas últimas décadas aos países para que sejam mais abertos, mais transparentes e mais colaborativos. Para esse mister, em agenda mais recente, a Comissão Europeia propõe introduzir nos Estados de forma mais sistemática novas práticas e estratégias inovadoras, inclusive promovendo design e pensamento para o futuro. Entende-se que o desenvolvimento com a alta participação cultural com a inclusão do cidadão na cocriação e codesign de políticas aumentam a legitimidade e eficiência no governo e, consequentemente, contribui positivamente para a democracia na sociedade. ${ }^{3}$

A grande questão que se coloca dentro desta revolução cultural e digital é como o setor público pode transformar o espírito burocrático dos servidores públicos para desenvolver medidas que perpassam pela implementação da visão gerencial, mas com foco na cultura da inovação. Este foi o desafio que a Justiça Federal de São Paulo se impôs desde 2016, mediante a implementação de um Programa de Gestão e Inovação (iNovaJusp), no qual a difusão da cultura da inovação constituiu pedra de toque para transformação do ambiente institucional na construção diária de novas alternativas para a prestação do serviço.

Neste processo, conforme veremos ao longo dos capítulos, o laboratório de inovação (iJuspLab), o primeiro do Poder Judiciário, transformou-se em espaço de criatividade, colaboração, engajamento, prospecção e difusão da cultura da inovação, constituindo forte e indispensável instrumental para repensar o nosso serviço público. O ambiente do iJuspLab é flexível e horizontal, próprio para desenvolver com metodologias de inovação serviços construídos a partir e para superar as expectativas do cidadão. Compartilhamos a nossa experiência na esperança de contribuir para o fortalecimento da inovação no setor público, em especial no Poder Judiciário.

\section{A GESTÃO JUDICIAL: É POSSÍVEL INOVAR NO JUDICIÁRIO?}

A gestão da inovação no Poder Judiciário encontra maiores óbices e desafios do que nos demais poderes. Com design organizacional de varas que remontam à formação do sistema judiciário no $\mathrm{Brasil}^{4}$, forte formalidade que compõe a liturgia

3 ALUJEVIC, Lucia Vesnic, et. Ali. The future of government 2030+. A cintizen Centric Perspective on New Government Models, 2019.

4 BOCHENEK, Antônio César e ZANONI, Luciana Ortiz T. C. A tecnologia e o novo design organizacional de Vara. 
dos julgamentos e estruturas hierarquizadas, a gestão da inovação ainda é vista com receio, talvez pela incompreensão do seu alcance de que inovar poderia comprometer as garantias constitucionais de independência e imparcialidade do magistrado. No entanto, é possível inovar construindo modelos que introduzam os ganhos das novas tecnologias, construam serviços de excelência e revejam modelos organizacionais, sem que resvale a necessária proteção à garantia dos magistrados.

Esse passo não é opção, dado que decorre do princípio da eficiência que impõe a todo o Poder Público a busca de soluções gerenciais e inovadoras para prestar um serviço eficiente. Dentro de uma leitura sistemática da Constituição, também o Judiciário deverá promover e incentivar o desenvolvimento científico, a pesquisa, a capacitação científica e tecnológica e a inovação (art. 218).

O Judiciário tem como missão institucional entregar a prestação jurisdicional dentro de uma duração razoável dos processos, constituindo o mesmo objetivo em relação aos processos administrativos - LXXVIII do artigo 5º, CF. Assim, com o desiderato de cumprir seu mister constitucional, deve o Judiciário empreender esforços gerenciais para aprimorar os serviços judiciários, com capacitação, investimento tecnológico e inovações, de forma que permita maior eficiência que, aliada à efetividade, atenda aos anseios sociais de um julgamento justo, que compreende o julgamento no tempo razoável do processo e com qualidade.

A gestão judicial contempla a gestão processual e administrativa. Adotamos ainda modelos organizacionais cujas bases são encontradas no modelo inaugural do Poder Judiciário no Brasil. O Judiciário expandiu-se ao longo do século passado em unidades judiciárias autônomas. Dada a sua complexidade administrativa, foi criada uma ampla estrutura para dar suporte à atividade das unidades judiciais. No entanto, ao fazer o diagnóstico dos problemas enfrentados na gestão administrativa verificamos que medidas gerenciais importantes ainda não estavam implementadas, como a gestão de dados, transparência, gestão dos recursos, planejamento, além de forte resistência à mudança gerencial e inovadora.

Na gestão processual também precisamos avançar na adoção de ferramentas gerenciais. O juiz é o gestor da unidade judicial (Lei Orgânica da Magistratura do Brasil - Lei Complementar n. 35 de 14 de março de 1979, e Lei n. 5.010, de 30 de maio de 1966). Dentro da nova perspectiva gerencial, passou-se a exigir do magistrado não apenas a responsabilidade pelas suas decisões no curso do processo e a legalidade na condução do processo, mas sobretudo, a prestação 
jurisdicional em tempo razoável e com qualidade. A accountability recai sobre o magistrado, que precisa estar preparado para a gestão, auxiliado pelo seu diretor, cuja capacitação é primordial para introduzir reformas gerenciais e inovadoras dentro do Judiciário.

De sorte que a implementação de mudanças gerenciais, organizacionais e nos serviços, constituem medidas indispensáveis para aprimoramento do Judiciário, seja na gestão administrativa, seja na gestão processual. Constitui terreno fértil à inovação o repensar os nossos modelos dentro de um olhar construído a partir das potencialidades da nova era, em que o conhecimento é de todos, a inovação é exponencial e o usuário está no centro da construção do serviço judicial.

A inovação no sistema de justiça foi sistematizada no movimento de legal design, que faz leitura dos potenciais da inovação para criação de novos serviços e organizações jurídicas mais satisfatórios, com a aplicação do design centrado no ser humano no direito. Design jurídico é a aplicação do design no mundo do direito, para tornar os sistemas e serviços jurídicos mais centrados no ser humano, utilizáveis e satisfatórios. ${ }^{5}$ A compreensão de que todo o sistema de justiça deve inovar ganhou no cenário nacional grandes mudanças. $\mathrm{O}$ desenvolvimento da inteligência artificial na seara da gestão de dados ganhou corpo nos escritórios de advocacia. Tal movimento tem impulsionado o Judiciário a buscar também a introdução de conceitos modernos gerenciais e tecnológicos.

Assim, não somente é possível inovar no setor público, mas constitui medida de legitimação do Poder Judiciário perante o cidadão, que em tempos de ampla transparência de dados, exige a prestação de um serviço público de melhor qualidade.

\section{COMO INOVAR NO PODER JUDICIÁRIO?}

Para uma instituição ser inovadora o laboratório de inovação constitui passo importante e inspira a inovação na instituição, mas deve estar ancorada em amplo programa de gestão e inovação, que assegure a inovação não apenas pontual e voluntária, mas sobretudo diária e em todos pontos da administração. A alta administração é o coração da mudança, o firme propósito de que a cultura da inovação seja o novo norte da gestão precisa ser sentido e transmitido. A liderança

5 O legal design foi sistematizado na Universidade de Stanford. Disponível em: <http://www. lawbydesign.co/en/legal-design/>. Acesso em: 06 mar.2019. 
precisa estar determinada em abrir espaços para que a pujança da mudança encontre a força propulsora da inovação que está, em verdade, no poder criativo de quem faz o serviço. ${ }^{6}$

Normalmente, até em decorrência da forte cultura burocrática, a normatização de um programa faz com que os servidores públicos se sintam "respaldados" a inovar. A Justiça Federal em São Paulo, após amplo diagnóstico dos problemas e procedimentos das atividades do administrativo central, desenhou um progra$\mathrm{ma}^{7}$ e materializou em portaria aspectos gerenciais e inovadores da gestão. ${ }^{8}$ No entanto, a normatização não tem o condão de materializar o envolvimento para a mudança.

É preciso transmitir a mensagem pela alta administração de que o órgão inicia uma nova fase, em que é possível questionar a utilidade dos procedimentos adotados. Os processos de trabalho podem e devem ser revistos, com eliminação de burocracias e implementação de mudanças que visem à eficiência. Para este passo é imprescindível que as áreas tenham os seus procedimentos mapeados, de forma que o conhecimento do trabalho seja de todos. A revisão dos processos deve ocorrer com base nos valores da inovação, pois a metodologia permite o aprofundamento dos problemas e sua reconstrução a partir da perspectiva do usuário, de forma colaborativa e em ambiente de testes.

Inovar não significa abandonar a reforma gerencial. Pelo contrário, a gestão estratégica bem desenhada e implementada abre mais espaço para a inovação. É preciso diagnosticar os problemas de todas as áreas, planejar o futuro, estabelecer que o conhecimento será de todos com o mapeamento dos processos de trabalho, vincular as necessidades ao orçamento, promover a gestão de dados e transparência. Todas essas medidas gerenciais podem ser lidas e transformadas em espaços de inovação.

${ }_{6}$ Recente estudo elaborado pelo OCDE, de Revisão das competências de inovação e liderança na alta administração pública do Brasil, destaca entre as habilidades fundamentais da liderança a necessidade de que "Líderes devem entender os métodos de inovação, seus paradigmas e estratégias, de modo a liderar apropriadamente, devem apoiar e abraçar soluçôes novas e diferentes", p. 12. O texto conclui ainda que "As habilidades de liderança para conduzir e promover a inovação são, portanto, forte determinante do sucesso da inovação no Brasil".

7 Disponível em: <http://www.jfsp.jus.br/inovajusp/>. Acesso em: 4 mar. 2019.

8 Portaria atualizada disponível em: <http://www.jfsp.jus.br/documentos/administrativo/ NUID/inovajusp/atos/portaria-2018-36.pdf>. Acesso em: 4 mar. 2019. 
A inovação trabalha em rede, o compartilhamento com outras instituições na mesma vibração permite a conexão com o espírito da mudança e a troca de experiências. A prospecção com o que está acontecendo no mundo contribui para a espiral de inovação que deve existir na instituição. Inovar hoje pode significar atraso amanhã, considerando o avanço exponencial da tecnologia e seus reflexos, como alteração dos formatos de organização e prestação de serviços. Por isso, canais de abertura de inovação constante contribui para frequente assimilação institucional da rápida e inevitável transformação das organizaçōes decorrentes da revolução digital.

Mas nada é mais importante para a cultura da inovação do que a construção coletiva e gestão compartilhada. A perspectiva de que todos os servidores contribuem para os avanços do serviço público faz com que as propostas de mudanças estejam conectadas com as necessidades e possibilidades, com forte percentual de sucesso. Quando construímos a solução em conjunto, projetamos na sua concretização, afastando o personalismo. Além disso, a inovação construída sob olhares multidisciplinares, a partir da perspectiva de que todos temos talentos, se traduz em melhores soluções, não pensadas nas perspectivas solitárias. Nesse sentido, juízes, servidores e demais atores envolvidos com o serviço, juntos em ambientes horizontais, favorecem a construção de inovações que aprimoram o serviço.

O olhar aprofundando para o usuário do serviço, e o pensar o serviço público a partir de sua perspectiva, legitima a atuação do poder público, cujo desiderato no Estado Democrático de Direito é o de entregar um serviço público que atenda às suas expectativas. Os processos de empatia que compõe as técnicas de inovação, revelam necessidades e expectativas ocultas ou que nunca foram sentidas. Este exercício de empatia constitui processo difícil, uma vez que o juiz e o servidor público estão habituados a desenvolver seus projetos dentro dos gabinetes na ótica de quem presta o serviço, e da forma, não raras vezes, que melhor atenda às suas possibilidades. Este exercício, portanto, inverte a forma de pensar e construir o serviço, certamente, proporcionando aprovação do serviço pelo usuário.

$\mathrm{O}$ isolamento do setor público estagnou a prestação do serviço, quase sempre impossibilitado de atender à necessidade social. Espaços governamentais podem se traduzir em plataforma de avanços. A abertura para projetos conjuntos com a sociedade, desde que se observe a transparência e a igualdade de participação, 
ampliam o potencial do Estado para a prestação do serviço. De sorte que a inovação pode vir de fora do Estado, o que também amplia a lupa sobre o nosso serviço, com uma perspectiva mais abrangente e qualificada.

Ademais, o receio do erro constitui fortes freios à inovação no órgão público, sobretudo em face da crítica do usuário. Bem por isso que as técnicas de inovação contemplam momento de prototipagem das soluções encontradas, que deve ser seguido de teste em pequena escala e somente depois introduzido de forma sistêmica.

Para adoção dessa nova perspectiva, compreende-se ser fundamental a qualificação dos juízes e servidores para a gestão do conhecimento e inovação, o que implica, segundo Roberto Agune, considerar temas como visão sistêmica, empreendedorismo, colaboração, criatividade, novos formatos organizacionais, novos métodos de trabalho e inovação em gestão, os quais devem compor a pauta de eventos da instituição como palestras, seminários, oficinas, prototipagem de soluções, realização de talk-show, exibição de vídeos, criação de sites etc. com vistas a sensibilizar tomadores de decisão para esse novo olhar.'

As Escolas de Servidores e Juízes devem ser incluídas no processo de mudança como facilitadoras para adoção desse novo pensar, no qual a inovação é o ponto central. Também a criação de áreas organizacionais especificas de inovação contribuem para o desenvolvimento de métodos e técnicas voltados para estimular a inovação, a criatividade, o trabalho em equipe e a criação, a prototipagem e a implementação de novos modelos, coordenando essas atividades dentro de uma organicidade.

É fundamental que a mudança venha com a demonstração efetiva da liderança do propósito de abrir espaços para aprimoramento do serviço, não apenas para inovações disruptivas e transformadoras, mas as inovações de menor porte, que muitas vezes provocam grandes resultados. É preciso estar perto em reuniōes periódicas, conferências, portas abertas dos gabinetes, diálogos constantes, prospecção, integração com a rede de inovação do setor público e privado e, principalmente, abrir espaços para que projetos inovadores recebam apoio e prosperem.

Por fim, a inovação vai além do processo judicial e administrativo eletrônicos. É comum resumirmos a inovação aos avanços tecnológicos, quando de-

9 AGUNE, Roberto. O governo do século XXI. A era do conhecimento e inovação. Dá pra fazer, p. 26. 
vem vir acompanhados de mudanças gerenciais, organizacionais e de serviços, sem os quais a eficiência encontra freios e não atinge sua capacidade exponencial de excelência do serviço. Conforme veremos em capítulo próprio, a inovação tem várias facetas, todas elas fundamentais para modernização do Poder Judiciário.

\section{A EXPERIÊNCIA DA JUSTIÇA FEDERAL SEÇÃO JUDICIÁRIA DE SÃo PAULO}

A Justiça Federal de São Paulo criou o primeiro laboratório de inovação do Poder Judiciário, dentro de um Programa de Gestão e Inovação (iNovaJusp) que forneceu as bases para que a inovação pudesse se consolidar dentro da administração. O iNovaJusp funda-se no triple: gestão estratégica, gestão da inovação e governanças integrada e participativa. A gestão estratégica compreende o planejamento estratégico situacional, o orçamento programa participativo e gestão por processos de trabalho a partir de valores da inovação. A gestão da inovação funda-se em valores de colaboração, foco no usuário e prototipagem.

Em junho de 2016, inspirados pelos fortes valores da inovação, nos propusemos a construir nosso laboratório de inovação no prazo de trinta dias. Premidos pela crise orçamentária e diagnosticada a realidade burocrática, demos um passo atrás para desenhar um programa de gestão e inovação, no qual traçamos objetivos para levar o administrativo central ao conhecimento institucional (diagnóstico dos problemas, desenho e compartilhamento dos procedimentos), planejamento (construído a partir da análise situacional), orçamento (com reflexos das necessidades levantadas em todas as 44 subseções e 5 prédios da Justiça Federal na capital, além da participação da sociedade por meio de audiência pública), além de formação da rede de governança.

Essa decisão foi fundamental para imprimir desde o início e em todas as searas da administração a gestão com valores da inovação. De pronto estabelecemos que todos os procedimentos deveriam ser mapeados, mas que estávamos num novo momento, no qual o conhecimento deveria ser de todos os servidores (e não apenas dos gestores), devendo os procedimentos deveriam ser conhecidos e revistos, com eliminação de burocracias desnecessárias, retrabalhos, prospecção de possibilidades em outras instituições públicas e privadas, mediante construção coletiva da área envolvida. $\mathrm{O}$ envolvimento nesse novo momento não foi opcional, mas meta a ser seguida, o que resultou em mapeamento de 100\% dos fluxos de trabalho em 
um ano. A partir deste momento, as áreas passaram a diagnosticar os fluxos mais emblemáticos, para serem revistos dentro do iJuspLab, com vistas à excelência do serviço. $^{10}$

Outro ponto nodal para a mudança foi o estabelecimento de uma rede de governança, na qual foi possível estabelecer as bases para uma gestão compartilhada entre as diversas áreas, e entre estas com representantes de juízes e servidores de cinco regiōes da Justiça Federal. Com isso, criou-se uma porta para o diálogo institucional, superando o isolamento das áreas, que trabalhavam compartimentadas e arrastavam problemas que dependiam de comunicação.

O modelo pode ser representado na seguinte engrenagem:

Figura 2. Engrenagens da inovação.

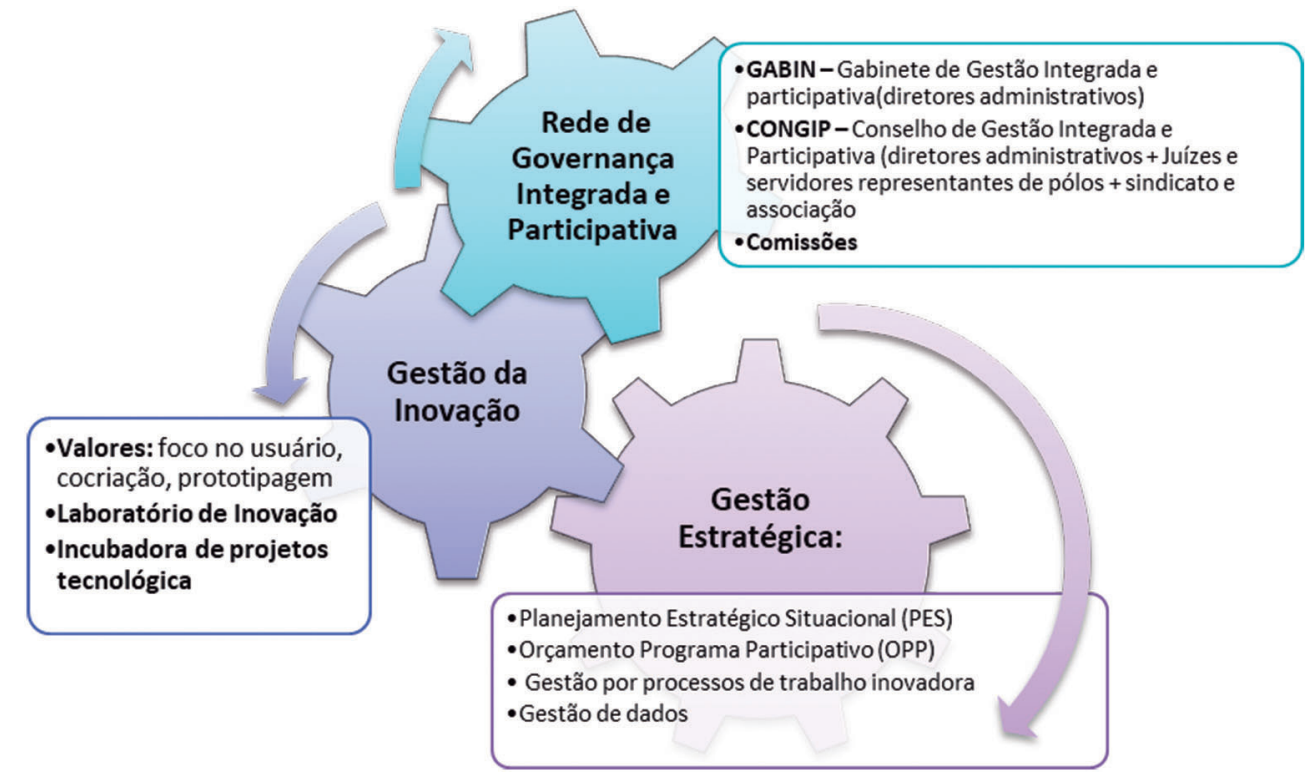

Fonte: Elaborada pela autoria.

10 O mapeamento dos fluxos de trabalho de todo o administrativo foi realizado no prazo de um ano. Para tanto foi facilitada a ferramenta Bizagi, com capacitação dos servidores com disponibilidade de 400 horas-aula. Depois, para o mapeamento foram feitas 300 horas-aula de capacitação de todos os servidores a fim de que a ferramenta fosse adotada no trabalho diário. Eliminados retrabalhos e burocracias desnecessárias, definidos novos fluxos, o desafio foi manter o uso e atualização dos fluxos. Além disso, as áreas escolhem uma vez por semestre um fluxo para aperfeiçoamento dentro do IjuspLab, visando a excelência do serviço. Todo os fluxos mapeados estão disponíveis em: <http://www.jfsp.jus.br/inovajusp/gestao-por-processos-de-trabalho-e-inovacao/>. Acesso em: 4 mar. 2019. 
De forma que quando da criação do iJuspLab, com todas as suas possibilidades, de horizontalidade, flexibilidade, ferramentas que favorecem a ideação e trabalho compartilhado e colaborativo, as bases para a mudança estavam implementadas. Desde o início, sob a mentoria de Roberto Agune e Alvaro Gregório, optou-se não por projetos mirabolantes e impactantes, mas a formação de uma equipe de laboratoristas que pudessem, independentemente de novos investimentos, instituir esta nova forma de fazer o serviço público, a partir da perspectiva do usuário, trabalho cocriado, e prototipagem, com metodologias de inovação, conforme serão abordados nos capítulos a seguir. Esta equipe de laboratoristas foi formada com voluntários de várias áreas, a fim de que este novo conceito chegasse no seio das subsecretarias. Hoje a equipe de laboratoristas se expandiu e as atividades no iJuspLab são intensas, a cada dia conquistando os coraçôes de quem pensa o seu serviço dentro deste ambiente inovador e mágico.

Figura 3. Imagem do iJuspLab.

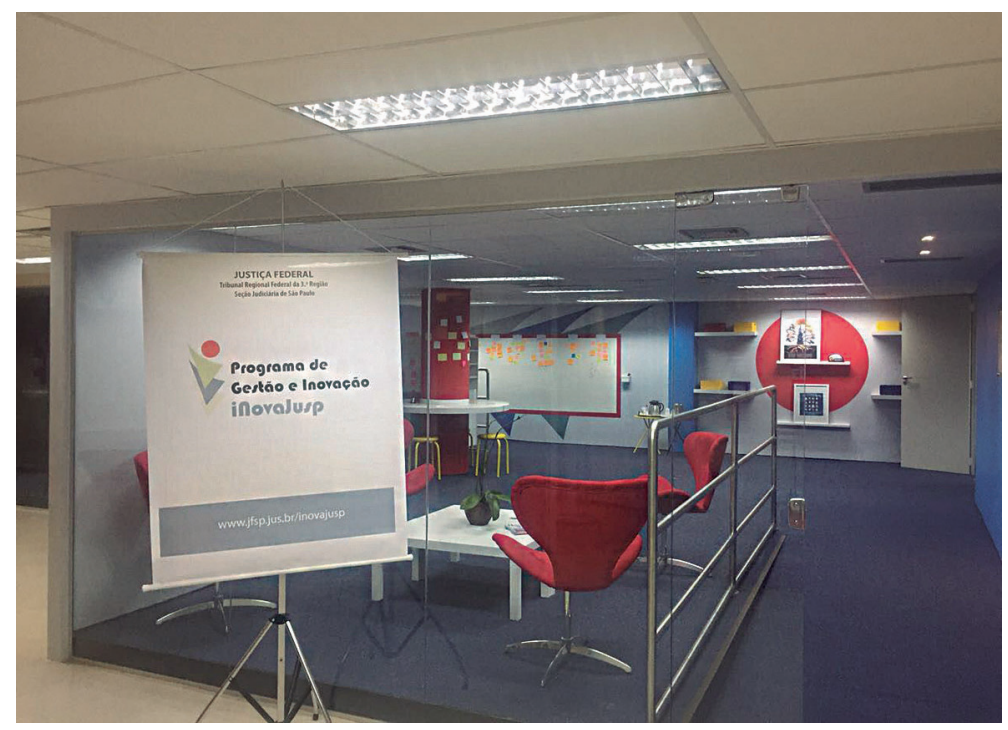

Fonte: Acervo da autoria.

O ijuspLab está no mapa na rede mundial do Design for Europe, conforme imagem abaixo. Integra a Rede Federal de Inovação, além de estar na rede Inovaday, que promove encontro mensais para introduzir iniciativas inovadoras para o setor público. Outras inciativas serão apresentadas nos demais capítulos. Tais iniciativas trazem rapidamente legitimidade e forte mudança interna, inspirando a organização para as possibilidades de inovação. 
Figura 4. Laboratórios de Inovação de Instituições Públicas no Mundo.

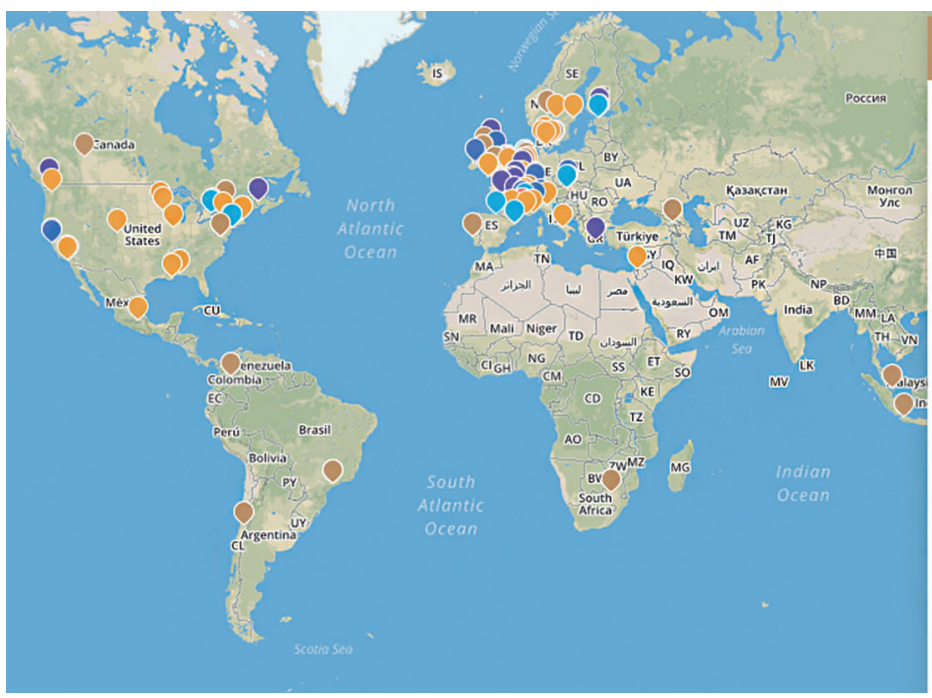

Brasil

Creation date

2016

Address

Rua Peixoto Gomide, 768 - $11^{\circ}$ andar -

Bairro Bela Vista - CEP 01409-903, São

Paulo

Website

www.jfsp.jus.br/inovajusp

The Federal Justice of São Paulo/Brazil congregates 53 federal courthouses located in 44 cities across the territory of the state of São Paulo, giving rise to 44 Judicial Subsections. It involves around $2,500,000$ of ongoing cases, 4,200 employees, more than 300 judges and a 470 million dollar annual budget.

Fonte: <http://publicsector-map.designforeurope.eu/en/>.

Um novo momento se estabeleceu dentro do IjuspLab, com a equipe de gestão de dados e a incubadora de projetos tecnológicos. Desde o início, para implementar o planejamento estratégico situacional e o orçamento programa participativo, tínhamos consciência de que era necessário organizar os dados, ter transparência e ferramentas tecnológicas que nos permitissem fazer gestão dos nossos recursos, além de ter instrumental para as decisões estratégicas. Entretanto, os desafios eram imensos. Essa mudança, contudo, ganhou contornos inovadores e estruturados, conforme irá expor o seu idealizador e autor em capítulo próprio.

Todo este trabalho de fomento à inovação, à gestão compartilhada, à prospecção, levou à criação de uma subsecretaria que reúne as áreas de inovação, conhecimento e comunicação. Sob o manto do iJuspLab, ponto central do qual emerge a inovação, e da sustentabilidade, em consonância à agenda 2030 da ONU, está a escola de servidores, a biblioteca (cujo conceito foi resignificado), a comunicação e a incubadora de projetos tecnológicos. A proposta é de gestão compartilhada, em que as áreas se auxiliam e constroem de forma colaborativa. Com a concessão de estrutura para a inovação, que reflete a forma de trabalho construída ao longo e junto com a propagação desta nova forma de pensar, acreditamos que está consolidada a inovação na nossa instituição. A nova Subsecretaria de Conhecimento, Comunicação e Tecnologia (UCIN) pode ser resumida na seguinte matriz: 
Figura 5. Trabalho integrado entre as áreas da Justiça Federal de São Paulo.

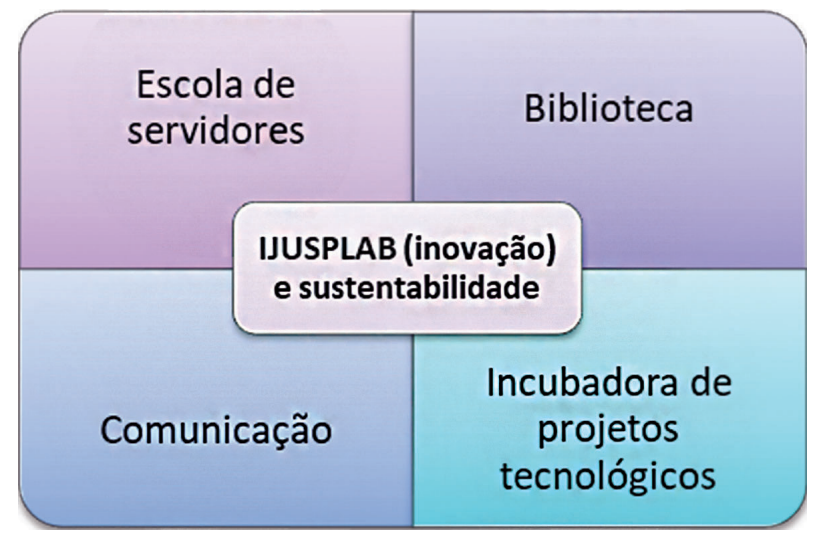

Fonte: Elaborada pela autoria.

E, por fim, destacamos que o iJuspLab é espaço também para se repensar a gestão processual. Em outubro de 2017, iniciou-se o desenvolvimento de um novo design organizacional de vara, com participação de desembargadores, juízes e servidores. O projeto sofreu aprimoramentos e hoje está finalizado para alta administração estudar a sua implementação. $\mathrm{O}$ projeto, pela sua relevância, será apresentado pelo coordenador dos trabalhos em capítulo próprio.

Recentemente, os laboratórios de inovação ganharam forte impulso e legitimidade com o desenvolvimento dos indicadores dos Objetivos de Desenvolvimento Sustentável (agenda 2030 da ONU). Em inédito projeto do Conselho Nacional de Justiça, os laboratórios de inovação e os centros de inteligência passaram a ser palco para ideação dos Objetivos de Desenvolvimento Sustentável (ODS) na perspectiva do Judiciário, a fim de que também este órgão contribua com a eficácia, eficiência e efetividade de políticas públicas voltadas para potencializar os direitos humanos e o desenvolvimento. As metodologias de inovação desenvolvidas em espaços horizontais e flexíveis permitem a construção de indicadores a partir da perspectiva do usuário, capazes de medir e dar visibilidade para problemas na condução dos processos judiciais cujos assuntos sejam relacionados aos ODS. Constituindo o laboratório porta de entrada para a perspectiva do cidadão na tomada de decisão de políticas públicas do Judiciário, nada mais significativo que a mais sensível das pautas ao cidadão, que visa justamente atender e dar efetividade a direitos fundamentais da vida humana, seja construída em ambiente em que os valores da inovação permitem sobrepujar essa perspectiva. 
•- Inovação no Judiciário

Inegável a revolução que a cultura da inovação está promovendo na Seção Judiciária de São Paulo, proposta que está avançando no Judiciário. Temos certeza de que os resultados são promissores. Hoje o iJuspLab cumpre a missão de nos permitir construir serviços de excelência, nos ajudando a solucionar problemas complexos. Quiçá amanhã tenhamos esses valores introjetados no nosso trabalho diário, quando os laboratórios de inovação terão cumprido a missão de nos fazer enxergar um serviço que atenda às expectativas de seu destinário, desirato institucional em um Estado Democrático de Direito.

\section{O QUE PODERIA TER SIDO MELHOR?}

Sempre fica a sensação de que poderíamos ter ido além, olhar que nos permite avançar e construir o futuro. Nesse auto reconhecimento, identificamos que o laboratório precisa intensificar suas atividades para levar as metodologias de inovação para as unidades judiciárias.

Como relatado, a estratégia foi a de iniciar o projeto nas áreas administrativas, a fim de que pudéssemos criar condições para que a Seção Judiciária tivesse um itime de servidores, capacitados para serem laboratoristas, e desenvolverem projetos no laboratório, além de disseminar e consolidar a inovação.

Agora, precisamos ampliar a capacitação dos juízes e servidores das varas judiciárias, que atuam na área fim (atividade jurisdicional), para utilizarem essas técnicas também na gestão judicial. Iniciamos um projeto para transformar espaços das unidades da justiça no interior ${ }^{11}$, em locais que propiciem a conciliação, atividades do centro de inteligência, capacitação, análise situacional para gestão de dados e atividades da incubadora de projetos tecnológicos. Todos esses aspectos demandam um espaço colaborativo, que propicie o diálogo e a construção de novos caminhos para se fazer justiça. Com esta sala multiuso teremos maiores condições de ampliar a cultura da inovação em toda a instituição. Demos os primeiros passos, mas ainda temos um longo caminho a percorrer.

\section{O QUE FOI BOM FAZER?}

A criação do laboratório de inovação contou com o entusiasmo de toda a equipe. A experiência de ser o primeiro laboratório de inovação do Judiciário, nos trouxe

11 A Seção Judiciária de São Paulo possui 44 subseções espalhadas na grande São Paulo e interior, além de 4 prédios com atividade jurisdicional na capital e 3 prédios com atividade administrativa. 
a responsabilidade de construir cada passo. Toda a equipe estava fortemente envolvida, superando os desafios, a equipe de gestão estratégica auxiliando nos normativos, a área de infraestrutura buscando soluçôes "caseiras"12 para o desafio de sair do papel um laboratório em plena crise orçamentária. O servidor e sua amiga artista plástica que colocaram a mão na massa para pintar as logomarcas e fazer o "jardim". O envolvimento e apoio da alta administração. Meus filhos que doaram os legos. A diretoria da associação de juízes federais (Ajufesp) que deliberou para colaborar com o orçamento. $\mathrm{O}$ apoio de pioneiros da inovação do setor público ${ }^{13}$ que trouxeram a boa nova da cultura da inovação. E, por fim, a presença dos curiosos nas primeiras atividades, que vieram voluntariamente conhecer a proposta e construir o primeiro projeto do laboratório. Momentos inesquecíveis, em que a colaboração de todos criou este novo espaço de ideação do serviço público no Judiciário. Um projeto despersonalizado, sem autoria, mas que ao mesmo tempo pertence a todos os juízes e servidores, cujo alicerce resultou da gestão compartilhada e colaborativa, sedimento sólido para um edifício que está sendo construído tijolo a tijolo, rumo à consolidação da cultura da inovação.

\section{BIBLIOGRAFIA}

AGUNE, Roberto; GREGÓRIO, Alvaro; NEVES, Ana (Coord.). Gestão do conhecimento $e$ inovação no setor público. Dá pra fazer. São Paulo: Secretaria de Planejamento e Desenvolvimento Regional, 2014. Disponível em: <http://igovsp.net/sp/da-pra-fazer. pdf>. Acesso em: 30 mar. 2019.

AIDH. Os objetivos de desenvolvimento sustentável da agenda 2030. Metas e indicadores rumo a um mundo mais humano. Cadernos AIDH, 01/2017.

ALUJEVIC, Lucia Vesnic et al. The future of government 2030+. A cintizen centric perspective on new government models, 2019. Disponível em: <https://publications. europa.eu/en/publication-detail/-/publication/9e71bf1b-3bd8-11e9-8d0401aa75ed71a1/language-en>. Acesso em: 30 mar.2019.

BOCHENEK, Antônio César; ZANONI, Luciana Ortiz T. C. A tecnologia e o novo design organizacional de Vara. Revista de Direito e as Novas Tecnologias. RT: São Paulo, v. 1, out.-dez. 2018.

12 Nossa subsecretaria de Manutenção de Infraestrutura foi fundamental para reformar o espaço. Além disso, contamos com a ajuda inestimável da arquiteta Elaine Loverra, autora do capítulo que tratará do design dos laboratórios.

13 Pudemos contar com a presença de Roberto Agune e Alvaro Gregório na inauguração, com uma conferência sobre inovação, e, a seguir, no laboratório, uma desconferência. 
•• Inovação no Judiciário

OSBORNE, Stephen P. e BROW, Louise. Innovation in public services: engaging with risk. In Handbook of Innovation in public services. UK: Edward Elgar Publishing, 2017.

POLLITT, Christopher; BOUCKAERT, Geert. Public management reform. A comparative analysis into the age of austerity. 4. ed. Oxford: University Press, 2017.

ZANONI, Luciana Ortiz T. C. Tecnologia no contexto da gestão a inovação no Poder Judiciário. Revista de Direito e as Novas Tecnologias. RT: São Paulo, v. 1 out.-dez. 2018.

ZANONI, Luciana Ortiz T. C. Os caminhos para uma governança democrática no Poder Judiciário. In: CONTI, José Mauricio (Coord.). Poder judiciário: orçamento, gestão e políticas públicas. São Paulo: Almedina, 2017.

OCDE. Revisão das competências de inovação e liderança na alta administração pública do Brasil, 2019. Editor Escola Nacional de Administração Pública (Enap). Disponível em: <http://repositorio.enap.gov.br/handle/1/3628>. Acesso em: $1^{\circ}$ maio 2019. 